\title{
NOVAS POSSIBILIDADES METODOLÓGICAS: A QUEBRA DOS PARADIGMAS QUALITATIVO E QUANTITATIVO EM PSICOLOGIA
}

\author{
NUEVAS POSIBILIDADES METODOLÓGICAS: LA RUPTURA DE LOS \\ PARADIGMAS CUALITATIVOS Y CUANTITATIVOS EN PSICOLOGÍA \\ NEW METHODOLOGICAL POSSIBILITIES: RUPTURE OF QUALITATIVE AND \\ QUANTITATIVE PARADIGMS IN PSYCHOLOGY \\ Edna Maria Peters Kahhale e Elisa Maria Barbosa Esper \\ Pontifícia Universidade Católica de São Paulo, São Paulo/SP, Brasil
}

\begin{abstract}
RESUMO
O presente relato propõe uma metodologia materialista dialética de análise de dados que rompe com os paradigmas qualitativos e quantitativos, numa perspectiva transdisciplinar e complexa, tomando como categorias analíticas historicidade, identidade, narcisismo, efemeridade e transitoriedade. Relata-se o caso "O Climatério na Contemporaneidade", que utilizou discursos e escalas padronizadas. Nos resultados, construiuse uma articulação entre os vários tipos de dados, a partir de uma análise estatística fatorial e de cluster para revelar tanto as semelhanças, quanto as diferenças entre as mulheres pesquisadas, além da formação de grupos qualitativos, de forma não arbitrária ou tendenciosa, baseada nas impressões dos pesquisadores. Demonstra-se criatividade metodológica que contempla a complexidade do objeto, ao construir um caminho metodológico original, baseado no pensamento dialético, que abarca tanto a diversidade quanto a totalidade do fenômeno, demonstrando que qualidade e quantidade, objetividade e subjetividade são duas faces de uma mesma moeda.
\end{abstract}

Palavras-chave: pesquisa qualitativa; pesquisa quantitativa; materialismo histórico e dialético; psicologia sócio histórica.

\section{RESUMEN}

Se propone un método materialista dialéctico de análisis de datos que rompe con los paradigmas cualitativos y cuantitativos, en una perspectiva transdisciplinaria y compleja, teniendo como categorías analíticas historicidad, identidad, narcisismo, efimeridad y transitoriedad. Presentamos el caso "El climaterio en la contemporaneidad", que utiliza discursos y escalas estandarizadas. En los resultados, hemos construido un vínculo entre los distintos tipos de datos, a partir de un análisis factorial y cluster para revelar similitudes y diferencias entre las mujeres encuestadas, además, la formación de grupos cualitativos, de forma no arbitraria o sesgada, basada en las impresiones de los investigadores. Se muestra creatividad metodológica, que incluye la complejidad del objeto, para construir un enfoque metodológico único, basado en el pensamiento dialéctico, que tanto abraza la diversidad como el fenómeno en su totalidad, lo que demuestra que la calidad y la cantidad, la objetividad y la subjetividad son dos caras de la misma moneda.

Palabras clave: investigación cualitativa; investigación cuantitativa; materialismo histórico y dialéctico; psicología sociohistórica.

\begin{abstract}
This report proposes a dialectic method of data analysis that breaks with the qualitative and quantitative paradigms in a complexity and transdisciplinary perspective taking as analytic categories historicity, gender relations, identity, narcissism, ephemerality and transitority. To illustrate this construction it is reported the case, "The Climacteric in Contemporary," which used standardized scales and speeches. In the analysis we constructed a linkage between the various types of results from a factor analysis and cluster to reveal both similarities and differences between the women surveyed, besides the formation of groups qualitative without being arbitrary or biased based the impressions of researchers. It is shown that creativity involves the methodological complexity of the object studied by building a unique methodological approach, based on dialectical thinking, which includes both the diversity as the totality of the phenomenon, showing that the quantity and quality and objectivity and subjectivity are two sides of a same phenomenon.
\end{abstract}

Keywords: quality research, quantity research, Dialectic and Historical Materialism; socio historical psychology. 
$\mathrm{O}$ presente relato propõe uma metodologia de análise de dados que integra dialeticamente os paradigmas qualitativo e quantitativo. Esta proposta, baseada na perspectiva da Psicologia Sócio- histórica, envolve os seguintes passos:

a) produção de dados discursivos, que podem ser obtidos a partir de entrevistas abertas, semidirigidas e ou narrativas de vida.

b) produção de dados quantitativos, obtidos a partir de escalas de medidas padronizadas para a população, e ou amostra estudada e de dados sócio demográficos.

c) análise dos discursos segundo metodologia de análise de conteúdo, de maneira a se obterem temas indicadores da diversidade qualitativa a que eles se referem, ou seja, núcleos de significação (Aguiar, 2001; Aguiar \& Ozella, 2006).

d) tabulação das escalas utilizadas segundo os critérios de padronização.

e) aglutinação de todos os dados qualitativos e quantitativos de maneira a identificar conjuntos qualitativos que descrevam a diversidade qualitativa do fenômeno estudado. Esse processo é feito por meio de análise estatística buscando agrupamentos por similaridades, integrando todos os dados quali-quanti.

f) apartir da aglutinação e identificação de clusters, retomar a análise dos discursos para descrevê-los indicando o contexto das diferentes qualidades obtidas. O agrupamento obtido é uma integração dos dados quantitativos e qualitativos do conjunto dos participantes do estudo. Cabe aqui uma nomeação de cada agrupamento que indique o aspecto do problema de pesquisa respondido, ou seja, como a qualidade se configura para os participantes do estudo.

Esta proposta é fruto das atividades desenvolvidas no laboratório de estudos de saúde e sexualidade ${ }^{1}$, buscando a construção de assistência integral em saúde, a partir de uma práxis que integra assistência e pesquisa, não priorizando a intervenção psicológica ou a pesquisa com intervenção, ou ainda a pesquisa-ação participante (Vázquez, 1967/ 2007; Thiollant, 1985; Vigotski,1991/1996; González Rey, 2007; Bock \& Gonçalves, 2009; Kahhale, Christovam, Esper, Salla, \& Anéas, 2010). O grande desafio do grupo era como articular as dimensões qualitativas e quantitativas na área da saúde, no diálogo disciplinar com outras áreas presentes na assistência cotidiana dos serviços de saúde. Como superar os embates quantidade $\mathrm{x}$ qualidade; objetivo $\mathrm{x}$ subjetivo numa perspectiva transdisciplinar e complexa (Vasconcelos, 2002; Kahhale \& Rosa, 2009; González Rey, 2003 ).

$\mathrm{O}$ enfrentamento da dicotomia quantidade $\mathrm{x}$ qualidade implica o debate das separações objetivo $\mathrm{x}$ subjetivo, indivíduo $\mathrm{x}$ sociedade e teoria $\mathrm{x}$ prática. Tais dicotomias explicitam categorias teórico-analíticas que precisam ser compreendidas. As categorias cumprem a função de auxiliar a dar visibilidade aos fenômenos, saindo do nível das aparências para apreender seu processo e concretude; suas relações e seu movimento. Assumiremos neste texto a compreensão de que categorias são abstrações, constituídas a partir da realidade e que orientam a investigação de processos, procurando apreender as múltiplas determinações dos fenômenos e seus nexos, bem como as relações contraditórias, que não se manifestam diretamente (Kahhale \& Rosa, 2009, p. 26; Aguiar, 2001, p. 95).

Para se chegar ao conhecimento, é necessário um método que permita desvendar, por trás da aparência, o fenômeno tal qual realmente é, suas contradições e o que o determina, que o leva a apresentar-se da maneira com que o faz. O materialismo histórico e dialético afirma que há um sujeito que capta um objeto e é capaz de interagir com ele, pois existe fora e independentemente dele, podendo ser apropriado e transformado pelo sujeito. Ele o faz através de uma ação intencionada sobre o objeto (a práxis), uma prática de apropriação e transformação do objeto; por isso deve ver, ouvir, sentir e pensar sobre o objeto em função da ação de transformação que tem sobre ele. O conhecimento, assim, parte do empírico e passa pelo racional para chegar ao concreto. Para isso, fará uso das leis e das categorias ${ }^{2}$ da dialética, buscando no empírico as suas contradições, chegando as suas determinações e, portanto, ao concreto (Vasquéz, 1967/2001; Kahhale, Peixoto, \& Gonçalves, 2002).

Ao longo do desenvolvimento das Ciências humanas, especialmente da Psicologia, construiu-se uma separação dicotômica entre indivíduo e sociedade (Kahhale \& Andriani, 2002; Gonçalves \& Bock, 2004; Kahhale, 2004; Kahhale \& Rosa, 2009). A fim de compreender e explicar o homem, sujeito individual, portador de uma experiência subjetiva particular, ao Psicologia se manteve dentro dos parâmetros da ciência moderna (objetiva, metódica, sistemática, empírica e experimental).

Tal perspectiva levou à divisão entre subjetividade e objetividade, expressa na oposição entre indivíduo e sociedade, vistos, portanto, como exteriores um ao outro. Criou-se uma noção de verdadeiro eu, e foram desvalorizadas as influências sociais e o processo 
histórico, que impedem um suposto e abstrato eu de ser como deveria: natural e verdadeiro (Kahhale, 2004; Kahhale \& Rosa, 2009).

É no desenvolvimento do capitalismo que as condições sócio históricas estão postas, para se questionar a noção de história como passagem do tempo da natureza e do sujeito natural. A questão da história passa a ser uma categoria analítica: historicidade. Ou seja, os atos e acontecimentos sociais e pessoais são produtos da ação dos homens entre si no mundo; são simbolizados e possuem intenções e significados construídos no processo de existência. Nesse processo, constitui-se como identidade e finalidade de si mesmo. É a contradição de si (eu) e não si (não eu), que fornece a identidade subjetiva, permitindo que eu me reconheça e me distinga dos Outros (isto acontece desde o nível celular até o social e familiar). Além disso, ao constituir sua identidade subjetiva, o sujeito está submetido a outros dois princípios, o da exclusão (só eu posso dizer “eu”, ninguém pode dizer por mim) e também o da inclusão (posso incluir outros na minha subjetividade e, então, passo a nomear "nós") (Kahhale \& Rosa, 2009).

É importante destacar que a práxis ou atividade humana é um processo de objetivação e subjetivação. O homem, como ser social, representa uma complexidade, que se expressa, por exemplo, na maneira como as demandas da dimensão corporal e orgânica são solucionadas e ou enfrentadas: sexo, fome, sede, sono, estimulação. Elas são respondidas ou solucionadas através de "ritos" sociais, regras e maneiras de agir; não se configuram da mesma maneira que para outros seres vivos, para os quais se dão pela dinâmica da genética e das condições ambientais e naturais (leis da natureza). Ou seja, a atividade humana é eminentemente social e histórica.

A atividade humana tem três aspectos fundamentais: ser orientada por um objetivo, fazer uso dos instrumentos de mediação e produzir algo que podemos caracterizar como elemento da cultura - seja por sua existência física seja por sua existência simbólica - e que consiste na objetivação do ser humano (Zanella, 2004). Essas três dimensões da atividade humana não seriam possíveis sem a articulação dialética com a categoria consciência. Atividade e consciência são processos recursivos. Os signos são produto da ação do próprio ser humano no processo de produção de sua vida material, decorrendo, portanto, da história da humanidade, e são instrumentos que a consciência se utiliza para operar. Uma vez apropriados ou subjetivados, caracterizam o psiquismo humano como sígnico e, em consequência, inexoravelmente social e pessoal, singular (Zanella, 2004).
É com a perspectiva acima descrita das articulações sujeito e objeto, indivíduo e sociedade, teoria e prática sob a perspectiva materialista histórica que se abordou o debate proposto da dicotomia qualidade $\mathrm{x}$ quantidade nas decisões de delineamento de pesquisa em Psicologia. Exemplificaremos, a partir da metodologia utilizada na pesquisa, "O climatério na Contemporaneidade" (Esper, 2005), que objetivou verificar se as mulheres no climatério são afetadas pelos fatores contemporâneos (narcisismo, efemeridade e transitoriedade). Isso significou apreender os significados e sentidos atribuídos pelas mulheres à sua vivência climatérica.

A vivência climatérica é um processo que explicita, na área da Psicologia da Saúde, o campo simbólico que constitui ou integra o sujeito, um sujeito que possui um corpo que pode adoecer, um sujeito que vive em determinadas condições que facilitam ou não seu adoecimento, e está inserido em uma cultura que lhe oferece referência para significar o que se passa com sua saúde e para lidar com a situação; um sujeito que se integra em um coletivo que é coprodutor (juntamente com ele) de sua situação ou condição de saúde. Todas essas condições e aspectos da vida social e das condições do corpo são significadas pelo sujeito. Sua condição somática terá um correspondente simbólico que se integra num todo facilitando, possibilitando ou dificultando sua recuperação. Nosso ponto de partida foram esses corpos femininos simbólicos, no momento do climatério, expressando a subjetividade de cada mulher participante do estudo, construída ao longo da sua história pessoal e social (Gonçalves, 1981; Kahhale, 2002, 2003).

Estudar o climatério na contemporaneidade significou defrontar-se com dimensões diversificadas e complementares decorrentes da intersecção de áreas como a Psicologia, a Medicina e a Sociologia. Essas áreas fazem leituras de dimensões diversas do fenômeno aqui estudado, e a colaboração de cada uma é fundamental para uma leitura mais complexa e completa do climatério. Assim, iniciamos com a caracterização do momento histórico no qual o fenômeno se insere .

A pós-modernidade, como alguns autores preferem denominar, expressa um conjunto de ideias produzidas a partir das complexificações no mundo social, político e econômico. Tais ideias se concretizam nas artes, teorias e produções científicas e no imaginário social em geral (Connor, 1993; Peixoto, 1998; Lyotard, 1986). A pós-modernidade tem como principal característica a pluralidade e é também conhecida como sociedade avançada, sociedade pósindustrial ou sociedade pós-moderna. Há consenso, 
entre os teóricos e historiadores estudiosos sobre esse período, que o mesmo acontece a partir do final da segunda guerra mundial (Harvey, 1996; Santos, 2000).

Baudrillard (1995) analisa a sociedade contemporânea concentrando-se no fenômeno do consumo, que obedece e responde a uma lógica do desejo e não da necessidade. O sujeito pós-moderno é submetido a um bombardeio maciço e aleatório de informações parciais que nunca constituem um todo, passando a ideia de um sujeito "patchwork": pulverizado, fragmentado. Há verdadeiro show de estímulos, no qual os protagonistas são o "designer", a moda, a publicidade e os meios de comunicação.

Para Lipovetsky (1990), o consumo aparece compondo a estrutura social de segregação e estratificação, e os sujeitos podem adquirir "valores signos" que lhe darão significantes sociais. É uma sociedade que sacraliza o novo, onde as necessidades são dirigidas e moldadas, e a autonomia de decisão fica eclipsada, em função de um condicionamento orquestrado.

No mundo pós-moderno, há um processo de simulação sedutora entre o individuo e a realidade, uma comunicação baseada em uma ação espetacular (Santos, 2000). Nesse sentido, Debord (1997, p. 67) afirma que a chamada "Sociedade do Espetáculo" fornece e apresenta os bens a serem desejados, criando-se a ilusão de potência individual, naturalizada e a-histórica.

Com os holofotes voltados para o indivíduo, há uma valorização do sujeito psicológico voltado para suas necessidades. Esse sujeito psicológico, segundo Lipovetsky (1983), resulta de intenso movimento e fascínio sem precedente pelo si mesmo, pelo autoconhecimento e pela autorrealização, potencializados pela cultura hedonista vigente. O homem pós-moderno é "psi" e lhe interessa um ego sem fronteiras, por meio do culto de uma singularidade subjetiva, de uma personalização identitária narcísica. O mito de Narciso é o que mais representa a sociedade contemporânea, em sua lógica individualista, refletida num corpo superinvestido (Esper, 2005, p. 51). O sujeito pós-moderno seria um narcisista diferenciado, com características particulares, tais como a desunificação, a fragmentação da personalidade em um processo de desreferencialização e desubstancialização do sujeito, diante da pluralidade contemporânea, resultando numa coexistência pacífica e apática com a diversidade (Santos, 2000).

Nesse contexto, há uma obsessão pelo corpo e pela saúde, havendo um descarte social de tudo o que não é belo, estético e saudável. Del Priore
(2000) observa que a mulher contemporânea investe no invólucro do seu corpo, aprisionada por um pressuposto de juventude eterna, invadida por uma lógica de estética perversa e tirania imagética. É preocupante ver como muitas mulheres tentam se transformar em algo que a sociedade contemporânea quer que elas sejam, entrando em uma contradição entre o corpo real e o corpo imaginário, simbólico. Para essa autora, a identificação contemporânea dos corpos com a beleza, juventude e saúde torna o envelhecer vergonhoso. Ela aponta que a estética hollywoodiana dos anos 20 se instaurou no imaginário feminino, construindo um modelo de beleza que tira de cena a mulher envelhecida.

A saída da cena principal denuncia certa invisibilidade que a meia idade feminina encerra e o quanto a mesma está impregnada pelos estereótipos que acompanham a aproximação da velhice, identificada com um padrão corporal desvalorizado. Essa invisibilidade é associada ao declínio da beleza, sendo interpretada e sentida por muitas mulheres como uma perda de status e poder. Greer (1994) fala sobre a angústia da aparência como um dos componentes de vivência da mulher climatérica.

Na sociedade contemporânea ocidental, na qual se inclui o Brasil, a representação social do climatério está associada ao envelhecimento. Os estudos de Hegg et al. (1994, p. 327), enfatizam que no "lato senso, durante o climatério, a mulher madura transformase em mulher idosa." As mulheres que se dedicaram exclusivamente aos cuidados da família têm que se defrontar com os preconceitos dessa associação, quando, nessa fase de suas vidas, decidem encarar possibilidades de inserção profissional. Embora as vivências sejam únicas, singulares e subjetivas para cada mulher, as trajetórias individuais trazem em seu bojo uma construção sociocultural, que sustenta uma representação da mulher climatérica como um ser desvalorizado, em relação aos padrões narcísicos ocidentais.

Mesmo para as mulheres que alcançaram sucesso profissional, não são menos desamparadoras as percepções sobre as marcas corporais que se delineiam, anunciando o envelhecimento. Laznik (2003, p. 94) afirma que "o corpo as abandona quando a sociedade as larga. Num mundo que não gosta nem da ideia nem da imagem do envelhecimento, têm de se defrontar com um olhar que as priva de reconhecimento."

Estar fora dos padrões estéticos idealizados e veiculados pela mídia pode fazer com que algumas mulheres de meia idade se sintam excluídas. A sensação de não pertencimento faz com que procurem meios extremos de transformações via cirurgias 
estéticas (Valadares et al., 2004). Porém, não se pode uniformizar as vulnerabilidades, pois a subjetividade de cada uma tem que ser considerada, na maneira pela qual fará elaborações para essa fase da sua vida. No entanto, as vivências anteriores, o que conquistou ou deixou de fazer, os investimentos emocionais feitos influenciarão nas escolhas para essa etapa. Ela poderá se beneficiar dos avanços da medicina, da tecnologia estética, sem se colocar em posição de escravidão aos padrões vigentes, obtendo maiores satisfações pessoais e qualidade de vida, ou entrar nessa roda viva narcísica, contemporânea transformando a vida em um simulacro que obedece à ideologia dominante.

O ambiente pós-moderno é povoado pela cibernética, a robótica industrial, a biologia molecular e pela medicina nuclear, num mundo traduzido por imagens e signos, cuja principal característica é ser regido pela informação, processada em "bits". A velocidade com que a tecnociência se estabeleceu desenhou uma nova configuração contemporânea, comandada pela transitoriedade e pela efemeridade A aceleração das mudanças na sociedade contemporânea tem consequências nas áreas pessoal, psicológica e social. A transitoriedade tem a ver com os processos contemporâneos de aceleração das mudanças

A transitoriedade é definida como uma "temporalidade da vida cotidiana que resulta em uma sensação de impermanência." (Toffler, 1970, p. 8). O autor aponta que essa sensação pode ser descrita em termos de mal-estar psicológico, sempre que se tiver diante da percepção de que as mudanças estão fora de controle. Ele denomina esse mal-estar de "doença da mudança", pois a intrusão da novidade constante altera as configurações já estabelecidas na subjetividade, criando novas configurações. No entanto, quando esse processo assume um ritmo acelerado, pode se tornar fonte de angústias, ansiedades, frustração e imobilização.

Essa velocidade, sobre a qual o sujeito não tem nenhuma ascendência, pode alterar o processo de subjetivação. Influencia na capacidade de incorporação de situações novas e desconhecidas utilizando a experiência prévia, como facilitadora desse processo, por se encontrar, continuamente, diante de algo inédito, que não se aplica ao que já está subjetivado.

Toffler (1970) afirma que não há dados consistentes em relação ao sujeito pós-moderno submetido às mudanças constantes, pois a percepção que se tem do tempo é subjetiva e associada ao ritmo do mundo interno. Esse estado de transitoriedade se refletiria em relações mais frágeis entre as pessoas, exacerbando $\mathrm{o}$ individualismo $\mathrm{e}$ fragilizando $\mathrm{o}$ laço social pois, "as coisas, os lugares, as ideias, as estruturas organizacionais se gastam mais rapidamente." (Toffler, 1970, p. 50). Estabelecese uma cultura do descartável: as ligações são temporárias, as coisas e as pessoas vão se suplantando. Essa sobrecarga de mudanças e novidades expõe, constantemente, o sujeito ao stress de ter que estar sempre se reconfigurando.

Incorporar ou participar do turbilhão contemporâneo de mudanças pode se tornar um complicador a mais para as mulheres no climatério que, por si só, já é uma época de mudanças significativas. Percebe-se certa ansiedade com relação à adoção de tratamentos medicamentosos para os sintomas que apresentam. A mídia está sempre noticiando dados contraditórios principalmente em relação à Terapia de Reposição Hormonal (TRH) que, ora é vista como panaceia universal para todos os males, e ora como grande vilã de distúrbios cardiovasculares e problemas relacionados à incidência de câncer de mama.

A TRH aparece, assim, de uma forma contraditória, espelhando as questões contemporâneas de uma realidade multifacetada e de uma medicina hiper especializada e compartimentada. Por trás da propaganda da utilização de hormônios, encontramse também os ideais narcísicos contemporâneos, pois a mesma encerra significados de manutenção de uma juventude e esperança ilusória de fecundidade, através da retomada de fluxos menstruais inócuos, do ponto de vista da reprodução humana. A TRH, com todos os seus resultados que vão se sobrepondo e se contradizendo, acaba por refletir a transitoriedade e a efemeridade pós-modernas, que estão no bojo de um individualismo e fragmentação social crescente.

Nesse contexto de verdades transitórias, a possibilidade de sentimentos de insegurança e desamparo se instalarem é muito grande. A transitoriedade e a efemeridade podem estar na base dos chamados distúrbios psicossomáticos de mulheres, maciçamente submetidas à super estimulações sensoriais e cognitivas. A velocidade do novo pode suscitar tanto distorções perceptivas, quanto interferir na capacidade de pensar, simbolizar, agir e sentir do sujeito.

Dessa forma, o contexto contemporâneo submete as mulheres às exaustivas mudanças, proporcionadas pelo avanço da tecnociência, fazendo com que as adaptações tenham que se suceder, fragilizando as verdades e o laço social. Tais mudanças ficam potencializadas quando associadas às modificações próprias dessa fase da vida como o esvaziamento das funções sociais. Se as vivências das mulheres ao longo da vida foram marcadas por intercorrências negativas, o climatério tenderá a ser problemático. 
Se a história de vida foi positiva, o climatério poderá ser ameno em sintomatologias, com possibilidades de desenvolvimento pessoal e vivências criativas.

Como se vê, essa fase de desenvolvimento do feminino encerra uma complexidade que coloca as mulheres diante de inúmeras bifurcações. O desvelamento desse contexto é importante no sentido de desmistificar ideias cultivadas de insuficiência para essa fase da vida, redimensionar e contextualizar a problemática do climatério na contemporaneidade. Isso significa apreender os significados e sentidos atribuídos pelas mulheres à sua vivência climatérica.

\section{Método}

A investigação de um tema complexo como o climatério na contemporaneidade foi considerado o "caso" a ser estudado, que exigia defrontar-se com dimensões diversificadas e complementares. Para abarcar a totalidade do fenômeno, a coleta de informações e produção de dados tomou direções tanto quantitativas quanto qualitativas, abarcando dimensões diversas imbricadas na subjetividade das mulheres climatéricas ${ }^{3}$.

Sujeitos: participaram 30 mulheres paulistanas, com faixa etária entre 40 e 55 anos, definida tecnicamente pela área da ginecologia, como sendo a do climatério. Houve uma preocupação de incluir mulheres com a idade entre 48 e 52 anos, porque é a faixa etária próxima da ocorrência média da menopausa nos países industrializados como o Brasil (Renó, 2002). $\mathrm{O}$ status conjugal ficou em aberto, para que a amostra contemplasse uma diversidade maior de experiências. Foram incluídas mulheres tanto com status menopáusico definido, quanto as que ainda menstruavam, o que gerou dados interessantes quanto ao significado da menstruação e de sua interrupção. O grupo participante contemplou mulheres com rendimento médio real em torno de $\mathrm{R} \$ 1.087,35$, resultante da média entre os salários dos empregados do setor público e do setor privado da Região Metropolitana de São Paulo, para as estimativas do mês de março de 2004 (IBGE, 2004). O objetivo foi incluir mulheres de uma faixa de renda e poder aquisitivo que permitisse utilizar produtos e tratamentos cosméticos, indicativos de uma preocupação em relação aos aspectos narcísicos contemporâneos, que se quis investigar.

\section{Instrumentos de coleta de informações e produção de dados}

A produção de dados de referência qualitativa objetivava alcançar os sentidos e significados das mulheres entrevistadas, ou seja, o que era ser uma mulher no climatério na contemporaneidade. Dessa forma, entrou-se em contato com crenças, sentimentos, valores, que as participantes haviam construído sobre sua experiência de vida em relação ao climatério.

Utilizou-se a entrevista como técnica de investigação qualitativa, que permitiu a construção de um discurso, para chegar a acessar a compreensão do climatério em relação às dimensões da sociedade contemporânea. Os depoimentos coletados permitiram a livre expressão do pensamento dessas mulheres, tendo sido um espaço de troca, apreensão e construção de significados. Possibilitou também verificar os modos de elaboração e ressignificação, utilizados pelas mulheres nessa fase da vida, considerando-se sua inserção na sociedade atual.

Para garantir a abrangência do que se propunha investigar, utilizou-se um roteiro de entrevista, abarcando temas da contemporaneidade: efemeridade, transitoriedade, percepção e vivência corporal, cuidados pessoais, relações afetivas, familiares e sociais.

Por outro lado, existiam dados oriundos de sintomatologias próprias do climatério e de qualidade de vida dessas mulheres, que poderiam ser quantificados, dando outra dimensão do real, a dimensão quantitativa, ou seja, de como o climatério se expressava corporalmente para essas mulheres a partir de escalas padronizadas para a população brasileira. Nesse sentido, utilizaram-se instrumentos que avaliaram, quantitativamente, os sintomas do climatério - Escala de avaliação da menopausa (Menopause Rating Scale $)^{4}$ - a qualidade de vida -Questionário genérico de avaliação de qualidade de vida (Short Form HealthSurvey - SF-36) $)^{5}$ e as condições socioeconômicas das mulheres investigadas.

\section{Análise dos dados}

A análise dos dados iniciou-se com tratamentos diferenciados para os dados qualitativos das entrevistas e para os dados quantitativos e socioeconômicos das escalas. As falas obtidas pelas entrevistas foram trabalhadas pela análise, na busca da aproximação com os sentidos subjetivos. A análise propiciou a formação de categorias temáticas, que resultaram na interpretação da fala para aproximação dos significados e sentidos, de acordo com a proposta de Aguiar (2001) e Aguiar e Ozela (2006). Os dados socioeconômicos e das escalas (MRS e SF-36) foram tabulados segundo a estatística descritiva, analisando-se frequências e tendências.

Percebeu-se, então, que se poderia alcançar a totalidade, apreender o concreto a partir dos 
pressupostos do materialismo dialético, a superação através da unidade dos contrários: quantidade e qualidade.

Marconi \& Lakatos (2000, p. 83) salientam que a dialética "analisa os objetos em movimento, ...pois nenhuma coisa está "acabada", encontrando-se sempre em via de se transformar, desenvolver ". A realidade é fonte inesgotável de transformações, e é esse fator que permite que os métodos de investigação e apreensão dos fatos também sofram alterações, permitindo abarcar a totalidade de um fenômeno em um dado momento, visto que a realidade é histórica, dinâmica e emergencial. Isso permite que os fenômenos possam ser investigados e reconhecidos em suas dimensões de totalidade, ou seja, de suas possibilidades quantitativas e qualitativas, apreendidas no seu movimento de diversidade na unidade contraditória. (González Rey, 1999; Demo, 2000; Kahhale \& Rosa, 2009).

Analisando o movimento metodológico utilizado nesse estudo, percebeu-se o movimento dialétic, no sentido da totalidade do fenômeno que incluía um grande número de dados, com diversidades oriundas da profundidade da análise de conteúdo de 30 entrevistas, de três escalas que avaliaram sintomas do climatério, a qualidade de vida e os dados sociodemográficos das mulheres pesquisadas. Dessa forma, tendo em vista que a base da análise dos resultados era qualitativa, considerou-se o número total de trinta (30) participantes adequado e suficiente para que os dados pudessem ser analisados, de forma a estabelecer uma rede de relações entre eles.

Após a análise de conteúdo dos discursos, para aprofundar a análise quali-quanti (quando se tem uma grande quantidade de dados e / ou participantes), utilizamos um software para análise em computador de textos (SPAD-T e SPAD-N), por meio de análise estatística, buscando a aglutinação por similaridade dos dados. Para a análise estatística de todo o material (temas obtidos nos discursos e resultados numéricos dos dados obtidos nas escalas e ou definidos quantitativamente), utilizou-se a análise fatorial para obter as similaridades, daí o nome clusters. De acordo com Mazza (2010), à luz de uma definição genérica, o cluster é um grupo de pessoas, animais, plantas, coisas, atividades, entre outros, que têm semelhanças entre si e variam juntas. $O$ conceito sugere a idéia de acoplamento, união, agregação, integração. Assim, ao procedermos a esse tipo de análise fatorial, conseguimos aprofundar a análise qualitativa desenvolvida, pois os "clusters" são definidos em função das semelhanças e correspondências dos significados e sentidos identificados entre os indivíduos da amostra, na análise do discurso. Ou seja, cada agrupamento (ou cluster) representa um conjunto de indivíduos com graus próximos em relação aos aspectos investigados na pesquisa/intervenção. Não nos interessa o peso do fator como seria numa análise estatística fatorial por correspondências múltiplas tradicional, mas a qualidade que está presente por trás dos fatores aglutinadores. Utilizamos a técnica como recurso para agrupar os sujeitos participantes da pesquisa, que apresentam similaridades não só de discurso mas em todos aspectos investigados tanto quali quanto quantitativamente. É esse conjunto que expressa uma qualidade própria, o significado e os sentidos buscados na investigação, que receberá um nome temático indicador da problemática pesquisada, que articula teoria e prática. $\mathrm{O}$ agrupamento ou cluster obtido por esse método integra esses dois tipos de dados e nos permite aprofundar a análise qualitativa dos discursos, oferecendo o contexto no qual se inserem. Em geral, na maioria das vezes, essa análise produz dois ou mais clusters. Essa proposta analítica visa superar a falsa dicotomia quantidade e qualidade, numa perspectiva do materialismo dialético. É aqui que ocorre o salto qualitativo ou superação da contradição quantidade x qualidade.

\section{Resultados}

Os resultados obtidos a partir da analise do discurso, segundo a proposta de Aguiar e Ozella (2006) originaram uma grande quantidade de dados qualitativos: 62 núcleos de significação extraídos da análise das entrevistas. Os núcleos obtidos foram: significados de estar no climatério, Significados relativos ao próprio envelhecimento, significado da idade para a sociedade, significado da idade para a mulher, autoestima, sexualidade, entrevista como desencadeadora de reflexões pessoais, narcisismo, transitoriedade e efemeridade. Como se objetivou apreender as contradições presentes nos discursos das mulheres, esses núcleos contemplavam tanto aspectos considerados positivos como negativos. Para uma visão dos significados envolvidos em cada núcleo, veja Quadro 1.

O conjunto de resultados nos apontava duas direções: de um lado, tínhamos dados sobre processos de significação e de sentido (González Rey, 2003; Bock \& Gonçalves, 2009), a partir da singularidade dos sujeitos que compunham a amostra; e de outro, dados numéricos que os colocavam em determinada posição e referência junto à padronizações de sujeitos submetidos às mesmas escalas quantitativas. Esse material era composto do discurso de 30 mulheres, que resultou em 1.806 conjuntos de frases (correspondentes 
aos núcleos de significação, descritos no Quadro1), às quais foram adicionadas mais 330 respostas resultantes dos dados quantitativos aferidos pelo MRS, além de outras 240 resultantes dos índices de qualidade de vida (SF-36), perfazendo um total de 2.376 dados a serem analisados.

Percebia-se, claramente, que um movimento dialético de superação da contradição quantidade $\mathrm{x}$ qualidade emergia como solução metodológica. Nesse sentido encontrou-se a posição de vários autores, que escrevem sobre metodologia e apontam para a falsa dicotomia entre quantidade e qualidade, que são na realidade um continuum compondo uma totalidade
(Demo, 1985; Mazzotti \& Gewandsznajder,1998; González Rey, 1999).

González Rey (1999) ressalta que, no campo da Psicologia, trabalhar com questões da subjetividade faz com que se avance na direção do desenvolvimento da produção de alternativas metodológicas diferenciadas. Esse autor salienta que a Psicologia tem precursores que já transitaram por esse caminho. Cita Piaget como autor que, inicialmente, pautou a construção de sua teoria em uma metodologia qualitativa e, posteriormente, desenvolveu uma série de trabalhos que se orientaram para a integração quantitativoqualitativo.

\section{Quadro 1. Núcleos de significados encontrados a partir da categoria analítica contemporaneidade}

\begin{tabular}{|c|c|}
\hline \multicolumn{2}{|c|}{ Significados de estar no climatério } \\
\hline Aspectos Positivos: Processo normal de desenvolvimento & $\begin{array}{l}\text { Aspetos Negativos: Aparecimento de sintomas do } \\
\text { climatério e Sentindo-se assustada }\end{array}$ \\
\hline \multicolumn{2}{|c|}{ Significados relativos ao próprio envelhecimento: envelhecimento como construto } \\
\hline $\begin{array}{l}\text { Positivo: Acúmulo de conhecimento e Evolução natural da } \\
\text { vida }\end{array}$ & $\begin{array}{l}\text { Negativo: Medo da dependência; Perda do vigor; } \\
\text { Medo do futuro }\end{array}$ \\
\hline \multicolumn{2}{|c|}{ Significado da idade para a sociedade } \\
\hline $\begin{array}{l}\text { Positivos: Maturidade; Sucesso profissional; Boa aparência; } \\
\text { Papel de Mãe }\end{array}$ & $\begin{array}{l}\text { Negativos: Desvalorização por envelhecer; Desva- } \\
\text { lorização pela diminuição da função; Preconceito; } \\
\text { Invisibilidade social }\end{array}$ \\
\hline \multicolumn{2}{|c|}{ Significado da idade para a mulher } \\
\hline Positivos: Maturidade e Experiência & $\begin{array}{l}\text { Negativos: Envelhecimento; Estranhamento de si } \\
\text { mesma; Esvaziamento da função materna }\end{array}$ \\
\hline \multicolumn{2}{|c|}{ Auto estima } \\
\hline $\begin{array}{l}\text { Positiva: Valorizada no trabalho, profissão; Valorizada pelo } \\
\text { companheiro; Valorizada pela aparência; Valorizada pela } \\
\text { família; Valorizada pela disposição }\end{array}$ & $\begin{array}{l}\text { Negativa: Desvalorizada pelo companheiro; Senti- } \\
\text { mento de desvalorização em relação à aparência }\end{array}$ \\
\hline \multicolumn{2}{|c|}{ Sexualidade } \\
\hline $\begin{array}{l}\text { Satisfeitas sexualmente: Melhora da qualidade/ intensidade } \\
\text { da relação; Entende melhor a própria sexualidade; Maior in- } \\
\text { timidade consigo mesma e com o parceiro. }\end{array}$ & $\begin{array}{l}\text { Insatisfeitas sexualmente: Sem atividade sexual; } \\
\text { Dificuldade no relacionamento conjugal interferindo } \\
\text { na sexualidade; Diminuição da Libido }\end{array}$ \\
\hline \multicolumn{2}{|c|}{ Entrevista como desencadeadora de reflexões pessoais } \\
\hline \multicolumn{2}{|c|}{ Narcisismo } \\
\hline $\begin{array}{l}\text { Afetadas pelas questões narcísicas, nos seguintes aspectos: } \\
\text { Perda da juventude; Perda da Beleza; Mudança da aparência }\end{array}$ & Não afetadas pelo narcisismo \\
\hline \multicolumn{2}{|c|}{ Transitoriedade } \\
\hline $\begin{array}{l}\text { Afetadas pela transitoriedade, Positivamente: Desafios e pos- } \\
\text { sibilidades de aprendizagem; Prazer em consumir; Avanço da } \\
\text { Tecnologia }\end{array}$ & $\begin{array}{l}\text { Negativamente: Tensão e insegurança; Dificuldade } \\
\text { de se adaptar, de acompanhar o ritmo das mudan- } \\
\text { ças; Incomodada pela mídia, pelo apelo ao consumo }\end{array}$ \\
\hline \multicolumn{2}{|c|}{ Efemeridade } \\
\hline Afetada positivamente & $\begin{array}{l}\text { Afetada negativamente: Valorização de coisas pas- } \\
\text { sageiras, Fragilidade dos relacionamentos; Descon- } \\
\text { trole do tempo, superficialidade do conhecimento; } \\
\text { Cultura do descartável; Consumismo e a sensação } \\
\text { de vazio }\end{array}$ \\
\hline
\end{tabular}


Vejamos como aprofundamos a análise dos discursos das mulheres, como apontado no Quadro 1, pois tais discursos continham aspectos contraditórios. Por exemplo, no tema Significados de estar no climatério, apareciam, ao mesmo tempo, aspectos positivos (processo normal de desenvolvimento) e aspectos negativos (aparecimento de sintomas do climatério e sentindo-se assustada), que também se expressavam nos resultados das escalas (por exemplo, aumento e diminuição de sintomas climatéricos; qualidade de vida afetada ou não por sintomas, bemestar, funcionalidade).

Emergiu então a questão: como agrupar as mulheres com discursos aparentemente semelhantes que não seguissem somente as impressões dos pesquisadores? Essa questão foi geradora e norteadora na busca de possibilidades de análise que dessem corpo e visibilidade aos pressupostos do materialismo histórico e dialético, que nos guiava no estudo do climatério na contemporaneidade. Ao se optar pela análise multifatorial de todos os dados obtidos, obtiveram-se arranjos, nos quais as semelhanças e as diversidades puderam ser contempladas, pois os agrupamentos eram das participantes da pesquisa e não das "variáveis" ou dimensões estudadas. Com essa mudança, o resultado da evidência estatística explicitou grupos com base na preponderância de indivíduos agrupados por certas qualidades, formando três grupos distintos de mulheres, nomeados após analisarmos as qualidades que as agrupavam em: "mulheres que choram", "mulheres em desenvolvimento" e "rainhas do lar". Os temas, núcleos de significado associados aos dados quantitativos das escalas, que aglutinou as mulheres foram: atitudes positivas frente à vida, família, investimentos em qualidade de vida, ter objetivos e planos, trabalho, parceiro, amigos e vida social, religiosidade, capacidade de adaptação.

\section{Quadro 2. Núcleos de significados encontrados a partir da análise de fatores que auxiliam as vivências do climatério}

\begin{tabular}{|c|}
\hline Atitudes positivas frente à vida \\
Família \\
Investimentos em qualidade de vida \\
Ter objetivos e planos \\
Trabalho \\
Parceiro \\
Amigos e vida social \\
Religiosidade \\
Capacidade de Adaptação
\end{tabular}

A partir dessa aglutinação, o próximo passo foi analisar o significado das qualidades que agrupavam as mulheres e responder ao objetivo da pesquisa de

Figura 1. Nuvem de Pontos, com a aglutinação das participantes em três grupos de acordo com suas qualidades em relação ao climatério

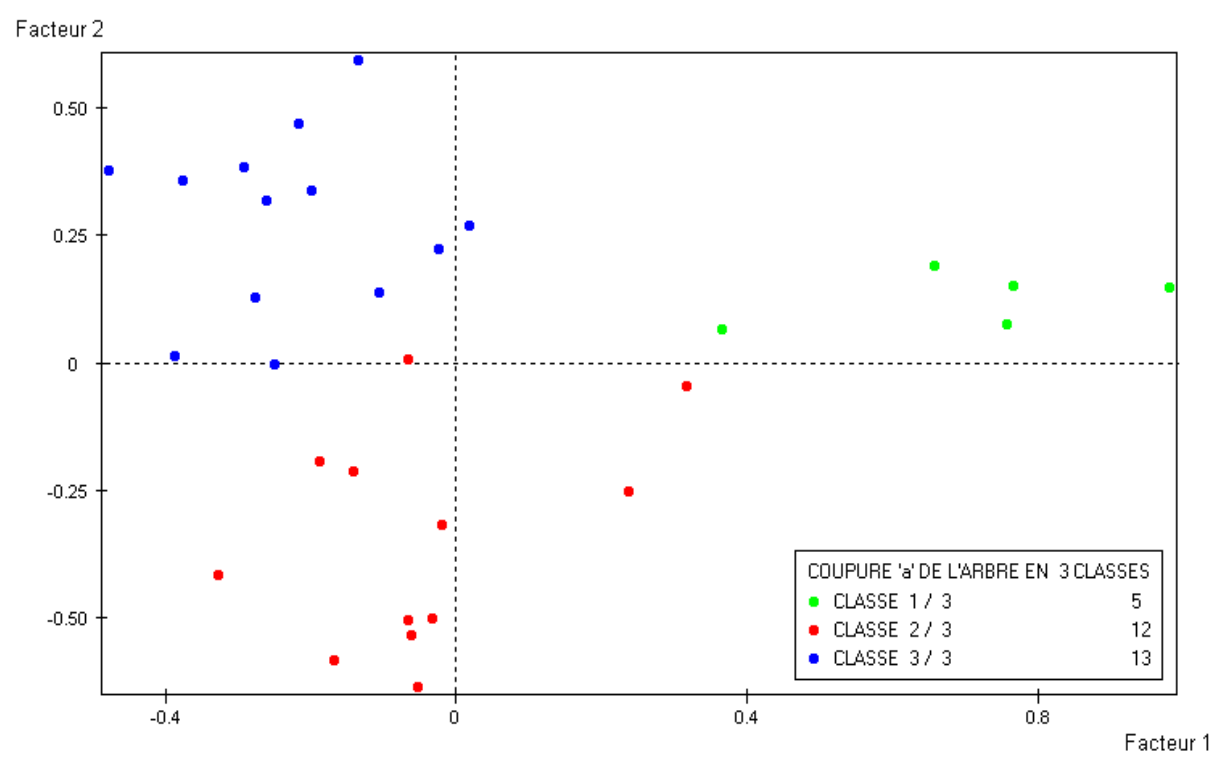

Cor Verde: grupo I - As que choram

Cor vermelha: grupo II - Mulheres em desenvolvimento

Cor azul: grupo III - Rainhas do Lar 
apreender os significados atribuídos à vivência do climatério. Uma visualização do resultado desse processo de aglutinação aparece na Figura 1 - "Nuvem de Pontos", com a aglutinação das mulheres em três grupos.

O que significam os três grupos: "mulheres que choram", "mulheres em desenvolvimento" e "rainhas do lar"? O que agrupou essas mulheres foi:

Grupo I - "Mulheres que choram": O perfil desse grupo de mulheres aponta para uma vulnerabilidade emocional, decorrente de poucos investimentos afetivos, que se refletem em insatisfações pessoais, com reflexo nas áreas familiar e profissional, quando ela existe. Percebeu-se certo sofrimento no enfrentamento dessa etapa da vida. Apresentaram-se resistentes ao novo, com pouca flexibilidade para suportar mudanças e com dificuldades para desenvolver projetos de vida compatíveis e factíveis: "Eu sou conservadora: eu sou da era da máquina de escrever, antes da elétrica. Eu sou totalmente de mil novecentos e nada. Odeio computador. Odeio detesto... Sou resistentíssima às mudanças"; "A tecnologia me incomoda também, porque eu não tenho muita capacidade de estar aprendendo a mexer com computador e esses negócios".

Os aspectos contemporâneos pareceram ser um complicador a mais nas vivências relativas ao climatério, agravando as questões dessa fase da vida. Em comparação aos outros grupos de mulheres, foram as que apresentaram sintomas mais expressivos, níveis de qualidade de vida comprometidos e adoecimentos psicossomáticos. Os dados demográficos desse grupo se mostraram bastante variados: não há predominância de uma faixa etária específica; são mulheres com idades entre 47 e 53 anos, com maior número de mulheres menopausadas. O grau de escolaridade variou do nível médio ao $3^{\circ}$ grau, a faixa de renda foi de $\mathrm{R} \$ 1.200,00$ a acima de $\mathrm{R} \$ 2.400,00$. A composição familiar abriga mulheres casadas com filhos e uma solteira sem filho. Portanto, os dados demográficos que se distribuíram de forma eclética, parecem não interferir no perfil desse grupo. O que pareceu ser o fator preponderante é a dinâmica da construção da vida dessas mulheres.

Do ponto de vista dos aspectos contemporâneos que se pretendeu investigar, esse grupo de mulheres mostrou-se afetado pelos três fatores contemporâneos investigados, ou seja, o narcisismo, a transitoriedade e a efemeridade. Quanto aos aspectos narcísicos, as mulheres desse grupo, apontaram um ressentimento em relação à constatações de perdas narcísicas como perda de beleza e da juventude, vivenciadas como feridas narcísicas. Percebeu-se um sofrimento psíquico atado ao estranhamento de si mesma no encontro com a própria imagem. Exemplo de falas dessas mulheres:
Eu estou tão confusa, tão atrapalhada que eu não saberia me definir; Quando a gente olha no espelho mais de perto e vê que tem manchas, rugas, olheiras, marcas senis, que a pele não está tão flexivel, isso deixa a gente preocupada, acha que vai ficar mais feia; A partir do momento que você se olha no espelho você nota certas diferenças, tem coisas que você não consegue fazer ou você começa a ficar com medo de fazer, como eu, que estou com medo de dirigir. Então você sente como que vai ser quando eu piorar, quando ficar mais velha: será que vou ser respeitada?; Tem hora que eu me vejo um horror, mas vou levando. Os homens hoje em dia quando vêm falar comigo é para pedir uma informação ... eles não me olham mais com interesse de paquerar.

Grupo II - "Mulheres em Desenvolvimento": O que é mais marcante e peculiar no perfil desse grupo é que são mulheres que se mostraram abertas para o novo, para as mudanças contemporâneas e novas experiências. Percebeu-se uma plasticidade emocional que as ajuda a fazer o enfrentamento dessa fase da vida, de forma a encarar a novidade transitória como um desafio, que promove aprendizagem e crescimento pessoal: "Eu acho que a velocidade é legal porque ela te estimula, te instiga, faz com que você fique esperta. Isso eu acho bacana"; "Eu costumo acompanhar a evolução. Sempre eu vou tentando me adaptar às coisas novas, em quase tudo eu costumo fazer isso: tanto no acompanhamento dos filhos como, no modo de vestir. Eu sempre tento acompanhar a evolução”.

Com isso, aproveitam o capital psíquico adquirido ao longo da vida, para viverem essa fase promovendo realizações pessoais, traçando projetos pessoais factíveis, indo ao encontro da realização de seus potenciais. "A minha vida sexual hoje, está melhor do que antes porque, com a maturidade, você aprende a se conhecer, aprende a se valorizar." O fato da grande maioria ter nível educacional superior, pode indicar para esse grupo que o fator educação pôde contribuir ou ser um facilitador na apreensão do mundo. Não foi um fator preponderante, mas pode ser um indicador a mais a ser pesquisado na história de mulheres no climatério. Todas as participantes do grupo disseram exercer atividade profissional, com nível de renda familiar acima de $\mathrm{R} \$ 2.400,00$. O estado civil é variado, englobando mulheres casadas, separadas e uma solteira. A faixa etária é bastante ampla, envolvendo mulheres com idades que vão dos 40 aos 53 anos tendo participantes que ainda menstruam e que já se encontram na menopausa. Com relação aos três aspectos investigados, esse grupo se mostrou afetado pelas questões contemporâneas. Do ponto de vista dos aspectos narcísicos, essas mulheres partiram de reflexões, analisando tanto posições subjetivas 
quanto aspectos globais da inserção feminina, na sociedade atual: "Eu acho que valoriza a informação, o conhecimento, a mulher no espaço público. A valorização e a luta pelos ideais, pela profissão $e$ também, pela beleza." Ressaltaram que existe uma desvalorização do envelhecimento associado à mulher de meia idade. Perceberam e apontaram a ideologia narcísica da atualidade na constatação da valorização da aparência, juventude e beleza.

a sociedade valoriza uma atitude pró-ativa, uma atitude de destaque, de vencedora em uma época que a própria sociedade te coloca como não vencedora: em termos de hormônio você está falindo, em termos físicos você está falindo. A sociedade vem te provar pela tecnologia, pelas descobertas da medicina que você está falindo - e quer que você seja pró-ativo.

A análise crítica e realista da imagem da figura climatérica na sociedade atual parece não influenciar negativamente na autoimagem. Nesse sentido, apresentaram-se com autoestima positiva, sentindo-se valorizadas em relação à boa aparência e ao reconhecimento de um exercício profissional competente.

Tem um nicho da sociedade que valoriza mulheres que se realizaram como eu. Eu me sinto uma mulher muito valorizada ... Eu acho que eu não aparento a idade que eu tenho e com isso a minha preocupação com idade, diminui muito.

Eu acho que profissionalmente a mulher que passou dos 40, já não tem mais campo. Só se realmente ela já batalhou muito, desde jovem e chegou a um lugar bem alto, como uma grande executiva, porque senão eu acho que a sociedade é para jovens mesmo.

$O$ fato de analisarem esse período da vida como um saldo positivo, não significou que não se sentissem afetadas com a percepção da perda da beleza e da juventude. No entanto, tais percepções não foram traduzidas como impossibilidades. Afirmaram reagir à constatação da realidade das perdas narcísicas, lançando mão da tecnologia existente no campo da estética, para protelar o envelhecimento. "coloquei na minha vida um tratamento que são plaquinhas de estimulação, que trabalha a musculatura para manter o tônus...cuido mais da minha pele com cremes especificos de dermatologistas. " É interessante notar que a faixa etária dessas mulheres é eclética, variando de 40 a 53 anos, englobando mulheres que estão no início do climatério, na pré- menopausa e já menopausadas. Esse dado aponta para a supremacia das vivências holísticas e construções subjetivas, em relação às previsões de degenerescência e desconfortos, relativas às perdas hormonais. Também desmistifica estereótipos relacionados à idade e às mulheres já menopausadas, como depressivas e improdutivas. Se considerarmos que são mulheres em pleno exercício de atividade profissional, evidencia-se a importância do exercício e do reconhecimento de uma função social plena.

Eu tenho que correr atrás...eu sei que é uma procura, então, por exemplo: eu estou terminando o mestrado e já estou conversando como seria o doutorado. Eu estou pensando no futuro, por mais que devesse estar correndo dele, pois. sei que o envelhecimento é certo.

Esses fatores aparecem refletidos em autoestima positiva, e na percepção e avaliação de uma boa qualidade de vida.

Eu acho que eu tive sucesso e, nesse sentido, a mídia não está cobrando nada que eu não possa dar, como um "corpicho" de 15, 18 anos. Eu sempre valorizei a inteligência porque eu acho que é uma boa arma para eu ter nessa fase da minha vida. Então, eu sempre cultivei o conhecimento e estou devidamente equipada para essa fase da minha vida.

Grupo III - "Rainhas do Lar" - as participantes desse grupo foram alinhadas por sua principal característica, ou seja, de estarem identificadas com os papéis de mãe e dona de casa, compondo o perfil de "Rainha do Lar". A ideia do perfil de "Rainha do Lar" para essas mulheres é corroborada pelos dados demográficos do grupo: todas possuem filhos, mais da metade são donas de casa, e, a maioria não fez curso universitário. A renda familiar acima de $\mathrm{R} \$ 2.400,00$, apareceu com um pequeno predomínio A faixa etária é eclética, e vai dos 42 aos 55 anos, evidenciando que não só as mulheres mais velhas, atendem às expectativas de "Rainha do Lar". Nesse sentido, a função materna é exercida em plenitude, mediante cuidados com a família nuclear e também com netos, traduzindo a ideologia da valorização do papel de mãe (Kahhale, 2003).

Eu sou uma peça importante na minha família, porque eu fico em casa. Eu cuido da minha casa, eu cuido dos meus netos porque a minha nora trabalha, a minha filha trabalha, então eu acho que eu sou muito importante, "né"! Pelo menos, meus netos não ficam sem mim. Eu que vou buscar na escola, eu que levo no futebol, no dentista. Então, eu me sinto assim uma pessoa importante.

Em relação aos aspectos narcísicos, a autoestima dessas mulheres mostrou estreita relação com a percepção de serem valorizadas pela família e pelo companheiro, indicando a importância do universo familiar. Como aspecto positivo de valorização social das mulheres na meia idade, ressaltaram a maturidade, 
em uma atitude de conformismo, demonstrando aceitação, tanto da inexorabilidade do tempo, quanto do ideário esperado pela sociedade para essa parte da população feminina, lembrando a ideia de Foucault (1986) de histerização do corpo feminino. "Envelhecer Ah! Eu acho que é consequência do tempo "né”! A gente vai perdendo a beleza, vai adquirindo experiência...se você tem a cabeça ocupada com os seus afazeres você não para “pra” pensar, e isso ajuda." Quanto aos aspectos negativos apontados pela sociedade para essa faixa etária, enfatizaram o preconceito que existe em relação à capacidade de trabalho da mulher madura, associado à improdutividade do envelhecimento. Tais aspectos foram salientados, principalmente, pelas mulheres que não exercem uma profissão.

Eu acho que a sociedade valoriza a parte profissional. Eu acho que dona de casa não tem valor. A sociedade não vê que a sua família anda porque você está atrás disso tudo. Você cuida de tudo para tudo caminhar certo. Então eu acho que nisso a gente é bem desvalorizada. Eu acho que o campo profissional valoriza ou se uma mulher é muito bonita fisicamente, fora isso, eu acho difícil valorizar; Você com 35, 40 anos você já está velha para o mercado, e eu acho que a gente tem experiência pra trabalhar ...é muita discriminação.

Quando em virtude da constatação de esvaziamento de sua função social, sentido principalmente em relação à emancipação dos filhos, relataram ir em busca de realizações profissionais e encontraram barreiras para o alcance desses objetivos.

eu acho que está passando muito rápido... as coisas estão passando muito rápido e eu deveria ter feito mais coisas ...é uma sensação de que já é um pouco tarde ... Está sempre faltando alguma coisa, de uma realização total como mulher.

\section{Discussão dos resultados}

Iniciaremos a discussão dos resultados, com as impressões das pesquisadoras (diretamente envolvidas neste trabalho) sobre a construção da pesquisa. Objetivase possibilitar ao leitor reflexões sobre o processo da construção do trabalho, desmistificando a rigidez sobre $\mathrm{o}$ distanciamento do pesquisador frente à realidade objetiva. Todos os cuidados foram tomados para que a produção de significados fosse sendo construída a partir do discurso das mulheres entrevistadas; porém, em alguns momentos, a pesquisadora não pôde se furtar de identificar-se com sujeitos e situações. Essa posição encontra eco em Maturana (2005) e Gonzalez Rey (2005), para quem a realidade só se configura a partir do olhar do observador que a decifra através de sua estrutura interna, no momento que a vivencia. Há uma troca interativa entre o observador e a realidade observada.

Nesse processo de construção de conhecimento em direção aos objetivos propostos, havia uma impressão inicial de que as questões contemporâneas fossem tão insidiosas que causariam adoecimentos. Tal hipótese não era de todo descabida, porque foi encontrada em duas mulheres. No entanto, à medida que a pesquisa avançava, essa ideia foi dando lugar à construção de um novo paradigma, em que as questões contemporâneas também eram eliciadoras de um desenvolvimento criativo, posição oposta às possibilidades de morbidade. Com isso, a experiência da pesquisadora foi enriquecida com desvelamentos e identificações que possibilitaram um avanço em seu processo de conhecimento e autoconhecimento.

A abordagem qualitativa, para a apreensão do climatério como "caso" a ser estudado, possibilitou dar à interpretação dos dados uma função heurística, engendrando novas redes de significados e de conceitos. Vale salientar que o fato da amostra ter sido composta por trinta participantes é bastante representativo para uma pesquisa qualitativa, tendo possibilitado, também, o emprego de tratamento estatístico, mediante utilização da análise fatorial e da análise de cluster, redimensionando a totalidade, na formação dos grupos.

A devolutiva feita de maneira informal a duas participantes que se identificaram adequadamente ao perfil do grupo onde estavam alocadas, pode ser indicativa da adequação dos resultados obtidos em relação aos dados da realidade. Portanto, as novas configurações resultantes desse estudo de caso apontam para possibilidades de equivalência qualitativa, transferibilidade, consistência e confirmabilidade conceitual (Mazzotti \& Gewandsznajder (1998).

É importante ressaltar que a utilização conjunta da análise fatorial e da análise de cluster permitiu revelar tanto as semelhanças quanto as diferenças entre as mulheres pesquisadas, além da formação de grupos de forma não arbitrária ou tendenciosa, baseada nas impressões das pesquisadoras. Com isso, a aglutinação das participantes pôde contemplar a totalidade na diversidade, possibilitando o aprofundamento da interpretação qualitativa dos dados. Através da análise qualitativa dos dados o olhar do pesquisador vai para além do fator que se expressa quantitativamente, recuperando e criando possibilidades de sentidos heurísticos que ultrapassam o valor estrito, expresso pelo dado coletado. Dessa forma, pode-se avançar para a tecitura de novas redes de significados. 
O que se quis demonstrar é que há possibilidades criativas de utilização metodológica que abarque temas contendo uma complexidade determinada pelo imbricamento de diversas áreas do conhecimento. No casodapesquisa "OClimatérionaContemporaneidade", a criação de um caminho metodológico original, baseado no materialismo histórico e dialético, pôde contemplar tanto a diversidade quanto a totalidade do fenômeno, demonstrando que qualidade e quantidade e objetividade e subjetividade são duas faces de uma mesma moeda. É um caminho promissor que pode ser trilhado em diferentes trabalhos de pesquisa.

\section{Notas}

\section{LESSEX/PUCSP}

2 Categorias da dialética: contradição, mediação, totalidade, essência/aparência, abstrato/concreto, singular/universal, conteúdo/forma. Elas não serão analisadas aqui porque fogem aos objetivos deste texto. No entanto, pode-se consultar Cheptulin (1982) ou Bock, Gonçalves, \& Furtado ( 2001) para um aprofundamento metodológico.

3 Parecer sobre o Projeto de Mestrado "O Climatério na Contemporaneidade" do Programa de Pós Graduação em Psicologia Clínica da PUC/SP. Aprovado em 21 de julho de 2004, pelo Comitê de Ética em Pesquisa da PUCSP. Presidente do Comitê de Ética em Pesquisa PUCSP: Prof. Dr Paulo Edgar Almeida Resende.

4 Escala de Avaliação da Menopausa foi validada por um grupo de pesquisadores: Heinemann, K; Ruebig, A.; Potthoff, P; Schneider, H. P. G.; Strelow, F.; Heinemann, L. A. J.; Do Minh T. (2004). The menopause rating scale: a methodological review. Health and Quality of Life Outcomes, 2-45 www.menopause -rating -scale.info

5 SF-36 foi adequado e validado para a população brasileira por Cicconelli,R. M.; Ferraz, M. B.; Santos,W.; Meinão, I; Quaresma, M.R. (1999) Tradução para a língua portuguesa e validação do questionário genérico de avaliação de qualidade de vida SF-36 (Brasil SF-36). Revista Brasileira de Reumatologia, 39(3), 143-149.

\section{Referências}

Aguiar, W. M. J. (2001). Consciência e atividade: categorias fundamentais da Psicologia Sócio Histórica. In A. M. B. Bock, M. G. M. Gonçalves, \& O. Furtado (Orgs.), Psicologia Sócio Histórica: uma perspectiva crítica em Psicologia (pp. 95-110). São Paulo: Cortez.

Aguiar, W. M. J. \& Ozella, S. (2006). Núcleos de significação como instrumento para apreensão da constituição dos sentidos. Psicologia: Ciência e Profissão, 26(2), 222-245.

Baudrillard, J. (1995). A sociedade do consumo. Rio de Janeiro: Elfos; Lisboa: Edições 70.

Bock, A. B. \& Gonçalves, M. M. (2009). A dimensão subjetiva da realidade. São Paulo: Cortez.

Bock, A. M. B., Gonçalves, M. G. M., \& Furtado, O. (Orgs.). (2001). Psicologia Sócio Histórica (uma perspectiva crítica em psicologia). São Paulo: Cortez.
Debord, G. (1997). A Sociedade do Espetáculo. Rio de Janeiro: Contraponto.

Del Priore, M. (2000). Corpo a corpo com a mulher: pequena história das transformações do corpo feminino no Brasil. São Paulo: Editora Senac.

Demo, P. (1985). Introdução à Metodologia da Ciência. São Paulo: Atlas.

Demo, P. (2000). Metodologia do conhecimento cientifico. São Paulo: Atlas.

Esper, E. M. B. (2005). O Climatério na Contemporaneidade. Dissertação de Mestrado, Programa de Pós-Graduação em Psicologia Clínica, Pontifícia Universidade Católica de São Paulo, SP

Foucault, M. (1986). La Voluntad de saber. México: Siglo Vinteuno.

Gonçalves, A. (1981) A saúde e a população: contribuição para o entendimento deste binômio em nosso meio. Ciência e Cultura, 33(11), 1425-1429.

Gonçalves, M. G. M. \& Bock. A. M. B. (2003). Indivíduosociedade: uma relação importante na psicologia social. In A. M. B. Bock (Org.), A perspectiva da Psicologia Sócio-Histórica na formação em Psicologia (pp. 41-99). Petrópolis, RJ: Vozes.

González Rey, F. (1999). La Investigación Cualitativa en Psicología: rumbos y desafios. São Paulo: EDUC.

González Rey, F. (2003). Sujeito e subjetividade: uma aproximação histórico-cultural. São Paulo: Pioneira Thomson Learning.

González Rey, F. (2005). Pesquisa qualitativa e subjetividade: os processos de construção da informação. São Paulo: Pioneira Thomson Learning.

González Rey, F. (2007). Psicoterapia, subjetividade e pósmodernidade: uma aproximação histórico-cultural. São Paulo: Pioneira Thomson Learning.

Greer, G. (1994). Mulher: maturidade e mudança. São Paulo: Augustus.

Harvey, D. (1996). Condição pós-moderna. São Paulo: Loyola. Hegg, R., Melo, N. R., \& Pinotti, M. (1994). Síndrome do Climatério - conceito, importância e epidemiologia. Revista Brasileira de Medicina, 51(3), 327-334.

Instituto Brasileiro de Geografia e Estatística - IBGE. (2004). Rendimento Médio Real da População da região Metropolitana de São Paulo. Acesso em 9 de maio, 2004, em www.ibge.gov.br

Kahhale, E. M. S. P. \& Andriani, A. G. P. (2002). - A constituição histórica da Psicologia como ciência. In E. M. S. P. Kahhale (Org.), A diversidade na Psicologia: uma construção teórica (pp. 75-96). São Paulo: Cortez.

Kahhale, E. M. S. P. \& Rosa, E. Z. (2009). A construção de um saber crítico em Psicologia. In A. Bock \& M. Gonçalves (Orgs.), Dimensão subjetiva da realidade: uma leitura sócio histórica (pp. 19-53). São Paulo: Cortez.

Kahhale, E. M. S.P., Christovam, C., Esper, E., Salla, M., \& Anéas, T. (2010). HIV/Aids: enfrentando o sofrimento psíquico. São Paulo: Cortez.

Kahhale, E. M. S. P., Peixoto, M. G., \& Gonçalves, M. G. M. (2002). A produção do conhecimento nas revoluções burguesas: aspectos relacionados à questão metodológica. In E. M. S. P. Kahhale (Org.), A diversidade na Psicologia: uma construção teórica (pp. 17-74). São Paulo: Cortez.

Kahhale, E. M. S. P. (2003). Psicologia na saúde: em busca de uma leitura crítica e de uma atuação compromissada. In A. M. B. Bock (Org.), A perspectiva sócio-histórica na formação em Psicologia (pp. 161-191). Petropólis, RJ: Vozes. 
Kahhale, E. M. S. P. (2004). Subjetividade e transformação social. In M. B. Wanderley \& I. I. M. Castanho e Oliveira (Orgs.), Trabalho com famílias: textos de apoio (Vol. 2, pp. 99-109). São Paulo: IEE-PUCSP.

Laznik, M. C. (2003). O Complexo de Jocasta: a feminilidade e a sexualidade sob o prisma da menopausa. Rio de Janeiro: Companhia de Freud.

Lipovestsky, G. (1983). A era do vazio: ensaio sobre o individualismo contemporâneo. Lisboa: Gallimard.

Lipovestsky, G. (1990). O império do efêmero: a moda e seu destino nas sociedades modernas. Barcelona: Anagrama.

Lyotard, J. (1986). O pós-moderno. Rio de Janeiro: José Olimpio.

Marconi, M. A. \& Lakatos, E. M. (2000). Metodologia Científica. São Paulo: Atlas.

Maturana, H. (2005). Las contribuciones de Humberto Maturana a las Ciências de la Complejidad e a la Psicología. Acesso em 20 de fevereiro, 2005, em www.inteco.cl/articulos/005

Mazza, S. R. (2010). Estresse, coping e qualidade de vida do trabalhador. Dissertação de Mestrado, Programa Pósgraduação em Psicologia Clínica, Pontifícia Universidade Católica de São Paulo, SP.

Mazzotti, A. J. A. \& Gewandsznajder, F. (1998). O método nas ciências naturais e sociais. São Paulo: Pioneira.

Peixoto, M. G. (1998). Condição pós-moderna/pósmodernidade. In M. G. Peixoto (Org.), A condição política na pós-modernidade: a questão da democracia (pp. 21-105). São Paulo: EDUC/FAPESP.

Renó, J. (2002). Estudo randomizado duplo cego de avaliação dos efeitos de terapia de reposição estrogênica sobre funções cognitivas e psicomotoras em mulheres menopausadas. Tese de Doutorado, Programa de Pós-graduação em Psiquiatria. Faculdade de Medicina da Universidade de São Paulo, SP.

Santos, J. F. (2000). O que é pós-modernismo (21 ${ }^{\mathrm{a}}$ ed.). São Paulo: Brasiliense.

Toffler, A. (1970). O Choque do Futuro. Rio de Janeiro: Record. Valadares, R., Moberdani, B., Jaggi, M., \& Brasil, S. (2004). Transformações Radicais. Revista Veja, 37(28), 84-93.
Vasconcelos, E. M. (2002). Complexidade e pesquisa intedisciplinar: epistemologia e metodologia operativa. Petrópolis, RJ: Vozes.

Vázquez, A. S. (2007). Filosofia da práxis (M. Moya, Trad.). Buenos Aires: Consejo Latinoamericano de Ciencias Sociais; São Paulo: Expressão Popular. (Original publicado em 1967) Vigotski, L. S. (1991). A formação social da mente. São Paulo: Martins Fontes. (Original publicado em 1962)

Vigotski, L. S. (1996). Teoria e método em Psicologia. São Paulo: Martins Fontes. (Original publicado em 1982)

Zanella, A. V. (2004). Atividade, significação e constituição do sujeito: considerações à luz da Psicologia Histórico-Cultural. Psicologia em Estudo, 9(1), 127-135.

Submissão em: 21/12/2012

Revisão em: 25/07/2013

Aceite em: 26/04/2014

Edna M. S. P. Kahhale é doutora em Psicologia Experimental pelo Instituto de Psicologia da USP; professora e pesquisadora do Depto de Métodos e Técnicas em Psicologia da Faculdade de Ciências Humanas e da Saúde, Curso de Psicologia da PUCSP e do Núcleo de Psicossomática e Psicologia Hospitalar do Programa de estudos Pós-Graduados em Psicologia Clínica da PUCSP; Coordenadora do LESSEX (Laboratório de Estudos de Saúde e Sexualidade). Endereço: Rua Diana, 700/142. São Paulo/SP, Brasil. CEP 05019-000. E-mail: ednakahhale@pucsp.br

Elisa M. B. Esper é doutora em Psicologia Clínica pela PUCSP. Pesquisadora do LESSEX (Laboratório de Estudos de Saúde e Sexualidade). E-mail: elisaesper@uol.com.br 